INTERNATIONAL DESIGN CONFERENCE - DESIGN 2018

https://doi.org/10.21278/idc.2018.0341

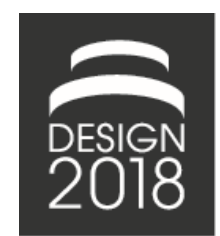

\title{
AGILE METHOD DEVELOPMENT: A LIVE-LAB CASE STUDY ON PRODUCT PROPERTIES FOR PROCESS PLANNING
}

\author{
A. Albers, N. Bursac, C. M. Eckert, B. Walter, M. Wilmsen and J. Heimicke
}

\begin{abstract}
Developing design methods can be described as a process similar to product development processes. Following agile approaches is worthwhile in order to identify relevant requirements of potential users at early stages of method's maturity. Live-Labs, as a controllable research environment located between laboratory and field studies, provide an environment whose results are neither too specific nor too generic. In this paper, an agile development of a method for process planning depending on product attributes is presented. The research took place in a Live-Lab with industrial participation.
\end{abstract}

Keywords: agile development, Live-Labs, design methodology, research methodologies and methods, design methods

\section{Introduction}

The development of methods and tools to support industry is one of the main objectives of engineering design research (Blessing and Chakrabarti, 2009), however in practise industry seems to use few of the design methods proposed by academia in the way that was intended by the creators of the methods. Many (e.g. Birkhofer et al., 2002; Jagtap et al., 2014) comment on the lack of uptake of methods in industry. This does not mean that engineers do not work in a systematic or methodical way but they employ fragments of methods that they have come across during their studies or past professional practise (Gericke et al., 2017). Introducing methods in industry can be problematic, because "methods tend to be too complex, abstract and theoretical"; "too much effort is needed to implement them"; "the immediate benefit is not perceived"; "methods do not fit the needs of designers and their working practices"; and "little or no training and support are provided" (Wallace, 2011). One of the underlying reasons is that researchers don't consider the needs of users adequately (Daalhuizen, 2014) and do not actively involve them in the development of methods. There can also be a lack of method evaluation and communication of the value of the methods (Jagtap et al., 2014). This paper proposes to apply an agile development approach to method development, where graduate students try out methods in projects, to gain frequent and rapid feedback on the methods and direct refinements of the method regarding strengths and weaknesses. Evaluating methods in industrial practise can be challenging. Vermaas, (2016b) argues that many design methods are derived from what is perceived best practise and validated through the experience of experts, who approve the methods. However, this is only sufficient of corroborate the effectiveness of the method (i.e. when I applied the method, it was useful) rather than the efficiency the method (i.e. it works fester for addressing my issue / solving my problem than other methods or current practice). Furthermore, both: the applicability of methods to different problems would need to be assessed and alternative methods as well as no method would need to be used to address the same problem (Vermaas, 2016a). Most methods are developed by researchers at 
universities, who have limited access to industry. Either methods are developed based an analysis of literature or on a small number of industrial case studies. While this has led to excellent methods, it has a limited potential for evaluating methods. Trying out immature methods might be a distraction to industry and potentially carry the risk of misleading results for industry. Even if it is possible to persuade a research team to use a method under development, it needs to have sufficient maturity that it is easy and efficient to use to avoid losing the good will of busy engineers. It is rarely possible to get exposure to different projects to test the scope of applicability of methods before they have reached a considerable degree of maturity. In consequence research efforts often stop with proposing a potential method rather than something that could be taken up by industry. This paper reports on repeated testing of methods in agile sprints, as used in the Live-Lab at the IPEK - Institute for Product Engineering at the KIT, which has been set up with the dual purpose of training product development master students how to work in industry projects and providing an environment, in which the IPEK researchers and the students themselves can develop and test methods (Albers et al., 2016a). The students are given project challenges from industry and work with industry experts in small teams on innovative solutions for industry. The students follow an agile development approach, whereby they develop up to four prototypes of their design. For each round of development, they have to plan, manage and document their activities. This provides a testing ground for new tools and methods, provided they have a level of maturity that they can be deployed with support by the method creators. In this context it is not enough to have an idea for a method, but it need to be supported with appropriate representations and processes. This gives the method researchers immediate and intuitive feedback on the applicability and benefit of their method as well as explicit feedback on the method. In this paper, we use the example of a method that scores product characteristics in order to plan design processes, based on a theoretical analysis of drivers and constraints as drivers of design processes (see Eckert and Stacey, 2014).

\section{Methods development}

The term method has been used since the beginning of systematic design research in the 19th century in Germany. Even though there is consensus that a method is a form of repeatable procedure that helps design engineers in carrying out their work, there has been little consensus over the precise meaning and nature of a method. E.g. Pahl and Beitz (Pahl et al., 2007, German version p. 784) define a method as a "systematic procedure with the intention to reach a specific goal" (in German "planmäßiges Vorgehen zum Erreichen eines bestimmten Ziels"). The meanings range from a loose collection of heuristics to a recipe for a particular activity. What is called a method also varies enormously in scale and ambition from all-encompassing approaches to product development like QFD to very specific methods for a specific task. Methods exist for all aspects of the product development process, some that are specific to a particular phase or a particular kind of problem (see Kumar, (2013) for general design methods; Cross and Roy (1989) and Albers et al. (2015) for a collection of classic engineering design methods; or Phadke, (1995) for specific robust engineering methods). The degree of specificity is a challenge associated with design methods, because it is rarely stated clearly as Vermaas (2016b) has pointed out. These books are a collection of successful methods, that have received sufficient recognition to be considered as worth including in a method collection, however many more methods are proposed in publications or $\mathrm{PhD}$ theses, which never get anywhere near introduction in industry. In the evaluation of a method it is also important to understand why and where the method failed. While this can arise from an inappropriate use or a context outside the scope, there can also be aspects of the method itself where not developed adequately. Considering this Gericke et al. (2017) broke a method down into the constituent components that work together for a method to be successful (see Figure 1). However, many methods have dedicated tools. To be useable, each method needs to come with a description that covers the following aspects (definitions from Gericke et al. (2017)):

- Core idea: The basic principle, technique or theory that the method employs.

- Representation: An object or other artefact that shows and stands for a system of objectives, i.e. intermediate results and deliverables created by using the method.

- Procedure: A description of the actions required to apply a method, for enabling the user of the method to do something more easily or with a sufficient guarantee of correctness, focusing on the sequence of actions and their completeness. 
- Intended use: A description of scope of a method, the coverage within, scope and expected benefit from using the method, informing the user about suitability of the method for a particular design task in a specific context.

- In engineering design research, a number of research methodology have been proposed such as

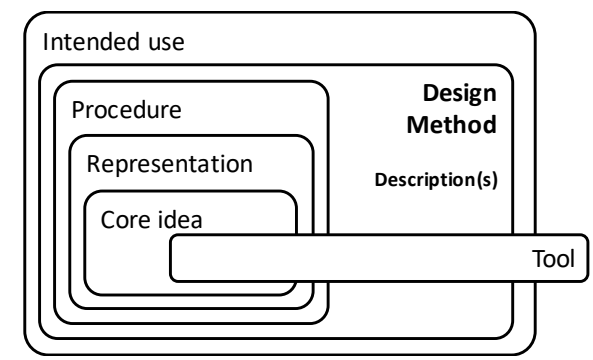

Figure 1. Elements of a method from Gericke et al. (2017)

Method development is a core element of several design research methodologies, which connect method development to other research activities. Design Research Methodology (DRM) (Blessing and Chakrabarti, 2009) proposes to identify a problem and criteria by which a solution to that problem is evaluated. Descriptive study I is then carried out to understand the problem and its context better, than an intervention, which can be a tool or method, is developed in the prescription phase and evaluated through a further case study in descriptive study II. In practice it is rarely possible to go through the entire process and if it is possible, it can be difficult to determine without doubt that an improvement is actually brought about by the new tools or method or if it was produced by other factors. The Spiral of Applied Research (Eckert et al., 2003) therefore splits the development of tools and methods into four phases: empirical studies, theory and method development, prototype development and introduction in the industry. Each of these are evaluated separately and don't need to be carried out in that order as insights can lead to the need for more empirical studies or theory development or move forward as an existing tool or method is identified as a solution to a current problem. Both approaches are based on an analysis of the current situation and a synthesis, in which a form of improvement is proposed and acknowledge that there can be considerable iteration, as new problems or insights require revisiting previous steps. More recently Marxen (2014) developed the integrated Design Support Development Model based on the iPeM - integrated Product engineering Model (Albers et al., 2016b). This approach separates research activities from a chronological sequence and recommends a selection of research methods for individual activities.

\subsection{Live-Lab environment}

Live-Labs are a half-way house between laboratory studies and field studies and help to resolve the conflict between too specific and too generic research results (Walter et al., 2016). Results from field studies are usually very company-specific and thus have restricted scope, while findings from classical laboratory environments are too general to be directly applied to industrial companies with an added value. The Live-Lab at the KIT employs an agile product development philosophy (Albers et al., 2018).

\subsection{Agile product development}

To assure that evolving customer requirements can be met and costs from late changes can be avoided, companies increasingly develop products on the basis of agile product development processes. Agile processes are characterized by a sequence of iterative sprints (for example 1 month), in which parallelized activities are undertaken. At the end of each sprint an incremental prototype of the product or various subsystems is created so that during the entire process the degree of maturity of the product is continuously and successively increased. Each incremental prototype increases the functionality or features or confidence of the previous prototype generation. This enables early evaluation of subsystems or components. Incremental development allows also for early feedback of customers. Agile development teams need to possess all the necessary skills to develop and validate the product. Agile approaches are well established in software development processes, and receive increasing attention in 
the development of mechatronic products, however as the boundary conditions are different (e.g. virtual vs. physical prototypes) modified forms established themselves. In this article the focus is set on the processes support in different phases of the typical overall process (Initiate, Discover, Deliver and Release). Popular agile approaches are briefly listed as a knowledge base for this goal:

- Design Thinking, which focusses on gaining deepest possible understanding of the end-user's needs, and aims at a rapid conception of solutions, an implementation in prototypes and early testing for further knowledge gain (Brown and Wyatt, 2010).

- Human Centered Design, which work with the users to gain a holistic understanding of the design problems that is addressed to develop systems, which are useful, usable and desirable for humans with the consistent focus on higher levels of humans' needs (Zhang and Dong, 2009).

- Scrum is a framework to support the improvement of project management and development practices to develop and sustain complex products. It has been used by leading software companies for object-oriented software and in product engineering as an agile process of trial and error to develop new systems within a team of non-experts (Schwaber and Sutherland, 2017).

- ASD - Agile Systems Design is a holistic, structuring approach for the agile development of mechatronic systems, the associated product strategy, validation systems and production systems, consisting of principles, methods and processes of PGE - Product Generation Engineering. It focuses on the consequent integration of PGE into the development process and creates a situation-specific balance between structuring and agile elements (Albers et al., 2018).

\subsection{Agile product development in Live-Labs by Co-Creation}

The traditional meaning the term labs was associated with environments in which controlled experiments can be carried out under manageable boundary conditions and controlled access., but is now also applied to much freer organisational forms such as Media Labs, City Labs, Living Labs and Green Labs. In these labs stakeholders from science (e.g. scientists from different disciplines), civil society (citizens from nongovernmental organisations, ...), economy (small, medium and large companies) as well as government representatives come together to focus on factors such as closeness to reality, practical application, flexibility, creativity, exploration, rapid gain of knowledge and openness. Several universities have started engineering labs (e.g. Design Lab at Griffith University). To focus on the integration of future customers and users in the different phases of the development process and often make use of methods of the User Centred Design and of Co-Creation. Often the goal is to generate new product profiles and product ideas, to have relevant customers test functionalities of products early and realistically, to increase the use of products and minimize development risks (Albers et al., 2018). In addition to other lab approaches, the Live-Lab at the KIT also enables new methods, processes and tools to be evaluated at an early stage and under realistic conditions to mature them sufficiently to be suitable for use in a company. The Live-Lab enables exploration and evaluation of methods and processes in a realistic environment, while at the same time being able to control the boundary conditions. Engineering students in the later stages of their degrees can work on real development tasks set by a company in a joint development project. They use various methods, such as creativity methods and valuation methods, and tools, e.g. software tools in the context of a structured product development process. Process data and insights are collected through observation, questioning, measurement and assessment of work results, etc. in accompanying studies about the methods and tools and the procedural, social and personal aspects of their usability. If a sufficiently number of subjects are involved in the Live-Lab, comparative studies with control groups are also possible. In contrast to traditional laboratory environments, in which subjects work on tasks under strictly controlled boundary conditions, the participants work on industry focussed engineering project and see themselves less as test subjects than as product developers, which makes their behaviour very realistic. The also work under tight deadlines and have to convince industry partners of the merits of their results. This makes them more critical of immature methods and processes, but happy to embrace methods that are beneficial to the success of the project. This ensures that the results of the experiments have significantly increased practical relevance compared to laboratory environments. The KIT developed three Live-Labs in product development: ProVIL - Product development in a Virtual Idea Lab, IP - Integrated Product development, and AIL - Agile Innovation Lab. All follow the ASD - approach and are offered as modules in the Master's degree in Mechanical Engineering (Albers et al., 2018). In all 
three Live-Labs, students work on a product development task, which is defined by a partner company with the objective of generating usable results (product concepts, mock-ups, prototypes, ...). The LiveLabs lasts between 12 to 19 weeks. The students work in teams of four to six people. After completing the two to five week sprints the students present their interim results in mile stone reviews to representatives of the partner company, who decide on the direction of the next spring. The students also attend lecturers and workshop. The grading largely focuses on learned process- and method knowledge in the field of product engineering, so that the actual project work is driven by the students' intrinsic motivation. All these measures serve to make the industrial development project as realistically as possible. The study presented in this paper was carried as part of ProVIL in the summer semester 2017. 48 students worked in eight teams from the beginning of May to the end of July on "Mobility Solutions for Future Sharing Economies", set as a development challenge by the project partner Centro Ricerche Fiat $(C R F)$. The development process of ProVIL includes a weekly online project survey, which all students have to fill in between Friday afternoon and Sunday evening. The project survey includes weekly recurring questions (for example, motivation, use of tools, etc.) as well as questions about the methods, processes and tools used. This provides a corpus of data that can be analysed.

\section{Research methodology}

As Figure 2 illustrates the research methodology can be seen on three levels: the overall methodology of agile method development, the development of a specific method and its application in the context of a specific project.

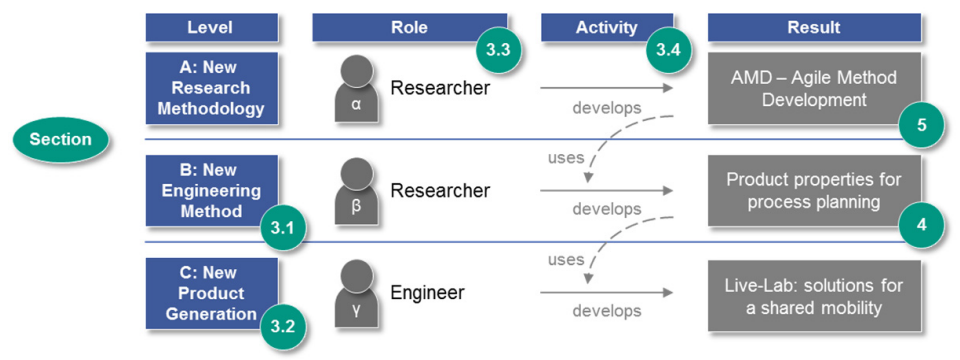

Figure 2. Overview of the research and structure the paper (Section 3)

The role of the participants changes on these level, while the participants can be seen as product development researchers on the first two level, they become engineers in a project, which is embedded its context. This highlighted in the diagram through a reference to product generation engineering which emphasise the existence of similar product insight or outside of the immediate context of the project. The results of the previous level can be applied in the next level. The Live-Lab acts as project context in our study. The sections that explain individual aspects are referenced in the diagram.

\subsection{The example method: Product characteristics}

The research started with the fundamental assumption that the design processes of products with similar characteristics also follow processes with similar characteristics and pose similar challenges to the developers. Eckert and Stacey (2014) argue that product constraints and characteristics could be used as a starting point to predict the behaviour of design processes and to inform process planning, because some high-level characteristics of the product lead to many of the activities. For example, all products that are safety critical have to go through activities of rigorous and often prescribed testing, which has to be considered in the development and determines many of the internal project deadlines. All products with a certain degree of complexity require a significant coordination effort and are likely to go through multiple rounds of convergent iteration and run the risk of churn, i.e. unproductive activities during additional iteration rounds (see Yassine et al., 2003). There is a clear link between product properties and the process by which they are being generated. Even though this is fundamental to product development, in that we aim at developing products that meet customer and user requirements in an appropriate way with the least effort and resources, we don't have a theoretical way of describing the 
link between products and processes. This method aims to develop a list of product characteristics from the key drivers of a wide variety of products to act as an input to the product planning process at the beginning of the process, based on the expected properties of the candidate design. This is complementary to current planning approaches which tend to start with either gateway processes working backwards from the expected deadline or the starting product in generational design and the activities expected to be required to update the product.

\subsection{ProVIL task 2017: Solutions for shared mobility}

This ProVIL cohort was working on the development of solutions for shared mobility with Fiat as a partners as part of the EU Project: Science2Society. While shared mobility is widely promoted multiple issues have to be addressed. It is still uncertain which future vehicle sharing concepts will be developed to meet a wide range of individual needs. The different student teams developed solutions ranging from business models for a car sharing franchise to a devise that sterilizes the insight of the car, as the students found more germs on the samples taken on steering wheel than in the universities restroom.

\subsection{The authors and roles}

The team of authors covers all three layers outlined in Figure 2:

- Level A - New Research Methodology: four of the authors work on establishing new research methodologies for design research. Thus, two authors already proposed research methodologies and three of them developed the ideas of Live-Labs for early evaluation of design research.

- Level B - New Engineering Method: four of the authors work on developing a new engineering method by using product properties for process planning. One author is working on product property methods. Four authors research on process modelling and planning.

- Level C - New Product Generation: two of the authors are working in ProVIL 2017. One author is running the ProVIL course and has been moderating the ProVIL sessions and therefore had an in-depth understanding of the teams and their knowledge needs. Another author was a member of the ProVIL student cohort and developed the spreadsheets.

\subsection{The steps of the research for this paper}

To develop and refine the method, the authors carried out the following steps:

1. The authors developed a list of product characteristics starting with a list provided in Eckert and Stacey (2014). This list was then expanded during a brainstorming meeting. It was decided to score the characteristics on a scale of 1 to 10

2. Twice, two authors got together and scored two products based on a list of properties. It proved very useful to compare two products getting a sense of the scale of the score. Again the list was refined. It was decided to use a product everybody was familiar with as reference product.

3. The list was then discussed in a meeting with 5 additional engineers, who discussed products they were familiar with and scored them in comparison to a car.

4. All participants found the discussion helpful in thinking through the products they were familiar with. At this point it was decided to apply the method in the context of the ProVIL project, which was running at this point and had one last iteration cycle to go through.

5. To make the method assessable to participants in ProVIL, the list was presented as excel spreadsheet to them. One of the authors, who herself was taking the ProVIL class, developed a first draft of the spreadsheet. This was discussed with all the co-authors and further developed. To make the scoring clearer to the ProVIL members, for each characteristic some well-known products were scored as calibration, see Figure 3. In addition to just scoring the factors, the participants would be asked to identify the 5 most important aspects of their product.

6. The method was presented to the students in a workshop two weeks before the end of their project to support them in the planning of the last activities. The majority of the authors took part in the workshop and observed groups of students.

7. In the last step a questionnaire was sent to the students to evaluate the method.

8. Evaluations of the questionnaire and lessons learned. 


\begin{tabular}{|c|c|c|c|c|c|c|c|c|c|c|c|c|c|c|}
\hline \multicolumn{4}{|c|}{ Product Attribut } & \multicolumn{11}{|c|}{ Examples for scale characteristics } \\
\hline$\#-$ & Attribute & 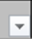 & Further Description & 0 - & $1-$ & 27 & 37 & $4=$ & $5=$ & $6=$ & $7=$ & 8 & $9-$ & 10 \\
\hline 8 & Lifetime of product & & $\begin{array}{l}\text { How long is the lifetime of } \\
\text { the product? }\end{array}$ & & $\begin{array}{l}\text { Piece of } \\
\text { pizza }\end{array}$ & $\begin{array}{l}\text { Disposab } \\
\text { le razor }\end{array}$ & & $\begin{array}{l}\text { Smartp } \\
\text { hone }\end{array}$ & & Car & & & & \begin{tabular}{|l} 
Tram \\
Infrastru \\
cture
\end{tabular} \\
\hline
\end{tabular}

Figure 3. Example line of the spread sheet

\section{Case study on product attributes}

There is an intuitive link between the characteristics of a product and its development process. Well known methods like $Q F D$ (e.g. Akao, 2004), develop product characteristics from the user requirements and identify characteristics that add value in the first stage and use them to identify critical issues in the following stage. This method is intended as a light touch method at the beginning of a product development process to predict aspects of the process and inform product planning. The method could therefore be used to select design alternatives according to the effort they require. In an industrial process it is anticipated that the method would be deployed at the beginning, as key product characteristics are decided very early in the process. The ProVIL students are working on high level product ideas and do not have a predecessor product, unless they choose one deliberately. Their challenge is to fit their ProVIL activities in with their busy student lives during exam season. As they were free to choose a product, their solutions differ widely from mechatronic solutions to pure service offerings and they therefore had to think through their development processes. They were provided with the classical iPeM to support their process planning (Albers et al., 2016b). The workshop was implemented at the beginning of the phase Specification, therefore the students already conducted successfully the phases Analyze, Identifying Potentials and Conception. For them the method was aimed at bridging the gap between their team's product idea and the process they needed to follow.

\subsection{Product attributes to enable / support process planning}

The method that the students followed consisted of three steps. The focus was on step 1.

1. Scoring the product on the basis of a list of product properties (supported by a spreadsheet)

2. Identifying the time each team member had before the end of ProVIL

3. Planning the remaining activities

The method included 51 characteristics covering different aspects of the product:

- 1 to 8 broadly characterized the product, its name, product class, industry sector; whether the product interacted directly with an end customers or supplied another company and its relation in the supply chain; the contribution of the product to the system it will be part of; the life cycle of the product and the overall life cycle of the system it is part of. These were scored with regards to example products, see Figure 3.

- 11 to 18 focusses on how much was already known about the product from previous products or known solution principles in terms of principle variation and embodiment variation, the percentage of carry over parts, to which extend the system architecture, the parametrization, the key equations, the functional architecture and the interfaces are known. These were scored as a percentage in $10 \%$ increments.

- 19 to 23 addresses the percentage of effort required by different engineering disciplines: software, mechanics, electronics and hydraulics

- 24 and 25 address the complexity of the product and the amount of subparts on a 1 to 10 scale

- 26 to 28 investigates the criticality of weight and geometry in the design

- 29 to 32 addresses the level of integration with other systems and its implications for the maintenance and retrofit of the product

- 33 to 36 addresses the interfaces with other elements of the product

- 37 to 42 covers the importance of different end user issues, such as intuitiveness, ergonomics and aesthetics

- 43 to 45 were concerns with influence on the validation, such as worth case scenarios or misuse of the product

- 46 to 51 covers a range of issues around the flexibility of the product. 
The participants were also asked to select the 5 most important characteristics and score them, concerning the probability of occurrence of problems regarding the team-specific system of resources and the product engineering task. Based on this, the participants identified the most critical problems defined for each alternative solution. Furthermore, the students selected the most suitable solution regarding their boundary conditions. Finally, they developed a plan for the following project phase based on the necessary tasks and available resources. Table 1 describes the elements of the method in terms of the elements of a method described by Gericke et al. (2017), see Figure 1.

Table 1. Product-property-method in terms of a Gericke et al. (2017) model

\begin{tabular}{|c|c|}
\hline Core idea & $\begin{array}{l}\text { A product is scored based on a list of potential properties to support planning the develop- } \\
\text { ment process }\end{array}$ \\
\hline Representation & A list of product characteristics and a score sheet \\
\hline Procedure & A series of steps was outlined in the power point presentation \\
\hline Use context & All engineering systems \\
\hline Tool & $\begin{array}{l}\text { An excel spreadsheet was developed to enable designers to score their product on a scale } \\
\text { of } 1 \text { to } 10 \text { and prioritize the issues that need to be addressed. Examples were also provided. }\end{array}$ \\
\hline
\end{tabular}

\subsection{Case study results}

To evaluate the design method, the case study was analysed from different points of view. The method representation, procedure, description and the intended use could be evaluated through direct feedback from the participants and through observations during the ProVIL session. In the course of the weekly survey within the ProVIL project, a questionnaire with in total 7 questions regarding the usefulness and applicability of the workshop and the possibilities of improvement for the future application of the workshop was conducted. 14 students participated in the survey, which also conducted the workshop. 7 of 8 teams were represented through at least one participant.

\subsubsection{Core idea}

The participants considered the core idea of the method in general to be useful and helpful regarding the identification of relevant product attributes of their product in development. The systematic analysis of the product properties was on average considered less useful then the ability to prioritise the activities of the current phase. This could have different reasons, one was that the participants were already in the final sprint and availability of resources to complete the project had become a major issue. However overall, they rated scoring product attributes and identifying available resources as useful in the project by making the planning of the phase more transparent to the whole team. The participants rated the clear assignment of the project tasks/ synchronisation within the team, prioritisation of the activities and the planning of the phase as the three most helpful results of the method. As the project ideas of the teams varied from mechatronic solutions to pure service offering, not all properties applied to each product.

\subsubsection{Representation}

The participants indicated that they found some properties difficult to score. This could have been because they were not applicable to their particular project ideas or they were ambiguously phrased. For example, the characteristics concerning the geometric size and the weight were marked as not rateable by 3 of the 8 participating teams, because they developed software solutions. In a future iteration it would make sense to make some of the properties depend on product categories. For example, for a product which scores $100 \%$ on software development amount, it might make sense to make some characteristics invisible. In the analysis of the characteristic software development stood out as having the highest impact on the planning. This might be, because three projects were purely software. Another reason might be, that nearly all participants had a mechanical engineering background, so software development is not one of their core competencies, which leads to an uncertainty on the project planning. 


\subsubsection{Procedure}

Based on observations during the case study and the feedback, it become clear that none of the teams could finish all tasks of the method within the given time of 2 hours. More time was the most frequently named improvement suggestion ( 6 of 11) for the application of the method in the next year's course. The teams also mentioned that the procedure forced them to carry out very detailed planning (2 of 11). For some team rough planning might have been sufficient to leave greater flexibility to the members.

\subsubsection{Description}

The method description was given to the participants orally backed up with slides. For a more formal evaluation of the method, it will be necessary to standardise description further.

\subsubsection{Intended use}

In the evaluation $21,4 \%$ of the participants rated the method as unhelpful or very unhelpful for the planning of the current project phase. $43 \%$ of the participants evaluated the prioritisation of product properties as neutral. Some participant commented that most of the teams had already planned the current phase a few days earlier. This leads to the conclusion, that the method was applied too late in the project.

\subsubsection{Tool}

During the case study, hardly any questions about the tools arose and each team was able to work with the tool easily. While that the current tool was suitable for this case study, it could not be used as a standalone tool in industry, since it needs explanation of a moderator, who would need to be specially trained or hired. Both require investment, which a company is at this stage of method development usually not willing to pay, since there is no experience or best practices so far to show the clear benefit of the method to a company. Thus, the design of the tool is strongly dependant of the intended use.

\section{Implication for agile method development}

Methods can be seen as products in their own right, so that the development of methods can also follow the philosophy of agile development with the same analysis and synthesis steps as product development. This changes when synthesis and analysis is carried out, as the goal is to validate at an early stage and go the several refinement and improvement cycles. Using the classical approach for the development of methods as advocated in DRM (see Section 2), a comprehensive literature study must first be carried out often followed by an empirical study of design practise, then it has to be ensured that there is an actual need for the method and from that a method is developed. Only now the validation can take place by applying it in a real industrial process, ideally the one in which the need was identified. For such a validation all the elements of a method need to be present including a detailed description of the methods is necessary and a functioning tool. After this effort, the scientist naturally hopes for positive feedback during method validation to complete his work. This introduced a confirmation bias, and the work tends to be corroborated rather than validated, and relies very heavily on experts as pointed by Vermaas (2016a). Validation thereby becomes a necessary evil instead of the hoped-for gain. The agile approach for method development aims to carry out a first validation very early after only a few days or weeks have been invested to generate knowledge and insights for the next iteration step. It is important to focus on the findings of the validation study in each sprint. Logically, in such an approach, the degree of maturity of the methods at the beginning is lower than with a conventional method developing approach. For this, however, the activities of the method development have been completed in explicit iteration loops which means the repeating after the validation study and detailing in the next step. This can be illustrated by the framework introduced in Section 2, where the iterative procedure of the method development in the phase model can be seen. 


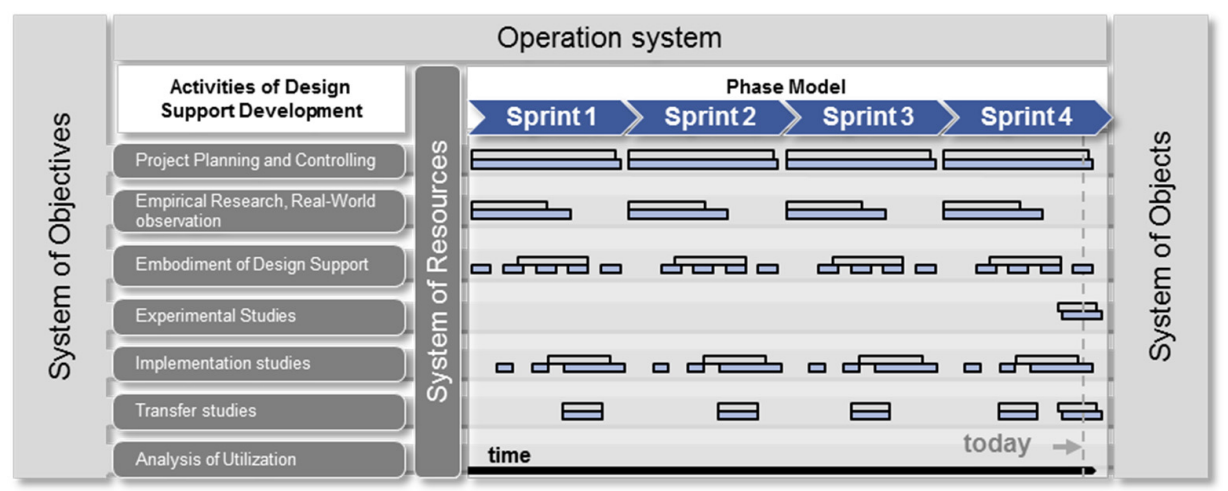

Figure 4. Activities of Design Support Development according to Marxen (2014)

Each sprint reflects different degrees of maturity of the elements of methods as illustrated in Table 2. The elements of the method might not mature at the same speed. For example, in the case study method the existing tool was working well after the first iteration, but the documentation required additional work. The logical steps of the individual increments of the elements are outlined in Table 2.

Table 2. Logical steps for the development of different elements of methods

\begin{tabular}{|c|l|l|l|l|l|}
\hline \multirow{2}{*}{ Core Idea } & Maturity & First idea & Detailed idea & Final idea & \\
\cline { 2 - 5 } & State of the Art & Google search & Data analyses & Abstracts of core papers & Literature review \\
\hline Representation & Representation & Post-its & Powerpoint & Flowchart, DSM & \\
\hline \multirow{2}{*}{ Procedure } & Technique & Moderation & Draft of procedure & Detailed procedure & Procedure with exceptions \\
\cline { 2 - 5 } & Study & Study & Live-Lab & Industry case study & Industry uses method in development project \\
\hline Description & Presentation & Powerpoint & Detailed description & Video & Teaching concept \\
\hline Intended Use & Situations & Possible situations & Test of the situations & Ideal situations & \\
\hline Tool & Medium & Poster & Excel & Implemented tool & Integrated in common tools \\
\hline
\end{tabular}

The rapidly implemented and in many places still immature results can lead to negative feedback, but also provide useful input for the next iterations. For example, as the sprint sessions are moderated, the moderator can offer support if the method is not adequately described and specify unclear steps. The use of posters and post-it notes also allows a spontaneous adaptation of the tools, if the users have problems with particular aspects of the method. The quick validation brings out, if particular aspects of the method are particularly useful in the method, for example the participants really liked the ability to prioritise characteristics that needed particular work. This interactive approach has the advantage that the users of the method can take up a Co-Creation role, because they can influence the design of the method. The idea of iterations of improvement also makes both the users and the creators of the method more willing to put up with partial failure of the method, because the investment is less for both, but the influence that they have is greater. Using the method with multiple groups in parallel, also allows an evaluation of the methods in different application contexts which enables an assessment of the scope of the method. For the case study method, it becomes clear that for purely software or service projects, a different list of properties would be required, or at a least the characteristics would need to be filtered by product type. This approach can also have the disadvantage that participants might feel rushed, because they have to invest time into multiple trial rounds. As the case study in this paper shows, methods as not applicable equally well to all stages of a development process, so that iterations of the methods might co-insight with activities where they add no value. For example, the characteristics of the product would remain the same after the concept has been selected and the participants might gain much benefit from the method. However, the method can be applied modified next year for the Live-Lab. Furthermore, iteration loops have to be integrated in a coherent description in order to of scientific texts, such as dissertations or papers, is not suitable for presenting this iterative procedure in concise text sections. To evaluate design methods with the presented agile approach, there are just a few questions which work for the evaluation of all types of design methods as e.g. the question whether the user likes the method and whether they can apply it easily. Methods support people and therefore processes, thus is the effect on the product quality often indirect through the process as e.g. reduction of iterations, more time to work on a product or greater maturity of the product. Although these aspects are also relevant for the method examined here, 
it was not possible to analyse this criterion, because of the very early evaluation of the method in the Live-Lab. Issues like less resources or shorter lead-time only apply to some methods and therefor the Live-Lab study needs to be adapted to examine these and other criteria in detail. As the human being is the centre of product development, all design processes, methods and tools should focus on the applicability and usability in the course of the validation of the design methods. Therefore it is sufficient for the very early validation of a method to focus on the criterion of the user appreciation and to use this as a filter for methods in an early stage. This stands in contrast to DRM, which wants to start with fixing the criteria against which success is measured. The presented approach uses graduate students specialising product development as representative for young engineers in companies without specific training. There are aspects of methods for which students are excellent predictors, e.g. usability of tools, logic coherence steps. As mentioned before, the criterion user appreciation is essential for a design method and needs to be addressed before the method is tested in industry. Through the real-world project character of Live-Labs, the students have real project pressure to complete the required results up to a defined deadline to present these to industrial representatives. Because of the mentoring of the students through experienced design researchers, the students are willing to learn new methods, but they also critically question the application of used methods and tend to adapt them to their problem situation. Thus, Live-Labs work as real-world validation environments to evaluate design methods in a very early stage before spending too much time into the elaboration of methods.

\section{Conclusion}

The example of evaluating a method which supports the planning of product development processes based on product attributes within a Live-Lab shows the big potentials of agile design research. We argue that the painful gap between methods based on knowledge acquired from literature, pure laboratory studies and observation of practice and its application in industry can be partly closed by an agile development of design methods using empirical studies accompanying product development projects at universities. Through this approach, the user is actively involved in the process of method development in the sense of Co-Creation, whereby important requirements are identified at an early stage that serve to align and adapt methods. On the one hand this requires courses which function as teaching courses, product development projects and research environments at the same time leading to the need for harmonizing the dimensions teaching, research and innovation. On the other hand, (and more important) it requires a mind-set change as it does often not follow a "clean", waterfall or cycle like research process but is more spontaneous, chaotic and less mature in its context of discovery. In return, results from agile empirical Live-Lab research can be generated much faster and under much better controllable conditions compared to field studies. It is evident that following agile research processes doesn't imply that quality criteria of empirical research have less importance or that the accuracy of description of the research methodology in use is rated lower. It just means that empirical research in total can be much quicker and mature when allowing intermediate results with lower maturity and a more explorative character as long as design researchers can justify what they did according to research standards. Insofar, agile design research and Live-Lab studies in particular shall not replace existing approaches, but can add specific value, when it ensures to comply quality criteria of empirical research.

\section{Acknowledgements}

We want to thank the EU for their support in the Live-Lab ProVIL within the project Science2Society.

\section{References}

Akao, Y. (2004), Quality function deployment: Integrating customer requirements into product design, Productivity Press, Cambridge Mass.

Albers, A., Bursac, N., Heimicke, J., Walter, B. and Reiß, N. (2018), "20 years of co-creation using case based learning. An integrated approach for teaching innovation and research in Product Generation Engineering", Proceedings of the 20th ICL Conference, Springer, pp. 636-647. https://doi.org/10.1007/978-3-319-73204-6_69

Albers, A., Bursac, N., Walter, B., Hahn, C. and Schröder, J. (2016a), "ProVIL - Produktentwicklung im virtuellen Ideenlabor", Entwerfen, Entwickeln, Erleben Werkzeuge und Methoden in Produktionsentwicklung und Design - Dresden, pp. 185-198. 
Albers, A., Reiß, N., Bursac, N. and Richter, T. (2016b), “iPeM - Integrated Product Engineering Model in Context of Product Generation Engineering”, Procedia CIRP, Vol. 50, pp. 100-105, https://doi.org/10.1016/j.procir.2016.04.168

Albers, A., Reiß, N., Bursac, N., Walter, B. and Gladysz, B. (2015), "InnoFox - Situationsspezifische Methodenempfehlung im Produktentstehungsprozess", Proceedings of Stuttgarter Symposium für Produktentwicklung.

Birkhofer, H., Kloberdanz, H., Berger, B. and Sauer, T. (2002), "Cleaning up Design Methods - Describing Methods Completely and Standardised”, Proceedings of DESIGN 2002 / 7th International Design Conference, Dubrovnik, Croatia.

Blessing, L.T.M. and Chakrabarti, A. (2009), DRM, a Design Research Methodology, Springer, Dordrecht, London. https://doi.org/10.1007/978-1-84882-587-1

Brown, T. and Wyatt, J. (2010), "Design Thinking for Social Innovation IDEO”, Development Outreach, Vol. 12 No. 1, pp. 29-43. https://doi.org/10.1596/1020-797X 12129

Cross, N. and Roy, R. (1989), Engineering Design Methods, 4 th ed., Wiley, New York.

Daalhuizen, J. (2014), Method Usage in Design - How methods function as mental tools for designers, PhD thesis, Technical University of Delft.

Eckert, C.M. and Stacey, M.K. (2014), "Constraints and Conditions. Drivers for Design Processes", In: Chakrabarti, A. (Ed.), An anthology of theories and models of design, Springer, London, pp. 395-415 https://doi.org/10.1007/978-1-4471-6338-1_19

Eckert, C.M., Stacey, M.K. and Clarkson, P.J. (2003), "The spiral of applied research. A methodological view on integrated design research", Proceedings of the 14th International Conference on Engineering Design (ICED 03), The Design Society, Glasgow.

Gericke, K., Eckert, C.M. and Stacey, M.K. (2017), "What do we need to say about a design method?", Proceedings of the 21st International Conference on Engineering Design (ICED 17), The Design Society, Glasgow, pp. 101-110.

Jagtap, S., Warell, A., Hiort, V., Motte, D. and Larrson, A. (2014), "Design methods and factors influencing their uptake in product development companies: A review", Proceedings of DESIGN 2014 / 13th International Design Conference, Dubrovnik, Croatia, The Design Society, Glasgow, pp. 231-240.

Kumar, V. (2013), 101 Design Methods: A Structured Approach for Driving Innovation in Your Organization, John Wiley \& Sons, Hoboken NJ.

Marxen, L. (2014), A Framework for Design Support Development based on the integrated Product Engineering Model iPeM, PhD thesis, Karlsruher Institut für Technologie.

Pahl, G., Beitz, W. and Feldhusen, J. (2007), Konstruktionslehre: Grundlagen erfolgreicher Produktentwicklung Methoden und Anwendung, 7th ed., Springer-Verlag Berlin Heidelberg, Berlin Heidelberg.

Phadke, M.S. (1995), Quality engineering using robust design, Prentice Hall PTR, Englewood Cliffs, NJ.

Schwaber, K. and Sutherland, J. (2017), The Scrum Guide. [online] Scrum. Available at: https://www.scrum.org/resources/scrum-guide (accessed n.d.).

Vermaas, P.E. (2016a), "A logical critique of the expert position in design research. Beyond expert justification of design methods and towards empirical validation", Design Science, Vol. 2 No. e7. https://doi.org/10.1017/dsj.2016.6

Vermaas, P.E. (2016b), "Towards Precedence that Justifies the Knowledge Claims of Design Methods", The Design Journal, Vol. 19 No. 2, pp. 195-204. https://doi.org/10.1080/14606925.2016.1129144

Wallace, K. (2011), “Tranferring Design Methods into Practice”, In: Birkhofer, H. (Ed.), The Future of Design Methodology, Springer-Verlag London Limited, London, pp. 239-248. https://doi.org/10.1007/978-0-85729615-3_21

Walter, B., Albers, A., Haupt, F. and Bursac, N. (2016), "Produktentwicklung im virtuellen Ideenlabor Konzipierung und Implementierung eines Live-Lab", Proceedings of the 27th Symposium Design for X, pp. 283-295.

Yassine, A., Joglekar, N., Braha, D., Eppinger, S. and Whitney, D. (2003), "Information hiding in product development. The design churn effect", Research in Engineering Design, Vol. 14 No. 3, pp. 145-161 https://doi.org/10.1007/s00163-003-0036-2

Zhang, T. and Dong, H. (2009), Human-centred design: An emergent conceptual model, Royal College of Art.

Dr.-Ing. Nikola Bursac

Karlsruhe Institute of Technology, Institute of Product Engineering

Kaiserstr. 10, 76131 Karlsruhe, Germany

Email: Nikola.Bursac@kit.edu 